\title{
HSP70/CD80 DNA vaccine inhibits airway remodeling by regulating the transcription factors T-bet and GATA-3 in a murine model of chronic asthma
}

\author{
Li Yan', Shi Xiao-Ling², Cheng Zheng-Yan³, Li Guo-Ping 4 , Zhong Sen5, Chen Zhuang²
}

${ }^{1}$ Molecular Medicine Experimental Center, Affiliated Hospital of Luzhou Medical College, Luzhou, Sichuan, China

2Laboratory of Infection and Immunity, Affiliated Hospital of Luzhou Medical College, Luzhou, Sichuan, China

${ }^{3}$ Sichuan Academy of Medical Sciences and Sichuan Provincial People's Hospital, Chengdu, Sichuan, China

${ }^{4}$ Inflammation and Allergic Diseases Research Unit, Affiliated Hospital of Luzhou Medical College, Luzhou, Sichuan, China

${ }^{5}$ Chengdu University of TCM, Chengdu, Sichuan, China

Submitted: 25 December 2011

Accepted: 16 April 2012

Arch Med Sci 2013; 9, 5: 906-915

DOI: $10.5114 /$ aoms.2013.33180

Copyright @ 2013 Termedia \& Banach

\begin{abstract}
Introduction: Airway remodeling is an important pathologic feature of chronic asthma. T-bet and GATA-3, the key transcription factors for differentiation toward Th1 and Th2 cells, play an important role in the pathogenesis of airway inflammation, airway hyperresponsiveness and airway remodeling. Previous studies showed that HSP70/CD80 DNA vaccine can reduce airway hyperresponsiveness and airway inflammation in acute asthmatic mice. The present study was designed to determine the effect of HSP70/CD80 DNA vaccine on airway remodeling through regulating the development of Th1/Th2.

Material and methods: Before being sensitized and challenged by ovalbumin, the $\mathrm{BALB} / \mathrm{c}$ mice were immunized with DNA vaccine. Lung tissues were assessed by histological examinations. Interferon- $\gamma$ (IFN- $\gamma$ )/interleukin-4 (IL-4) levels in bronchoalveolar lavage fluid were determined by ELISA and expressions of IFN- $\gamma$, IL-4, T-bet and GATA-3 in spleen were evaluated by real-time polymerase chain reaction.

Results: Chronic asthmatic mice had higher airway hyperresponsiveness, a thicker airway wall, more PAS-positive goblet cells, more subepithelial extracellular matrix deposition and more proliferating airway smooth muscle (ASM)-like cells than control mice $(p<0.05)$. Compared with the chronic asthmatic mice, the treatment with HSP70/CD80 DNA vaccine could reduce airway hyperreactivity, mucus secretion, subepithelial collagen deposition, and smooth muscle cell proliferation $(p<0.05)$. DNA vaccination also increased levels of IFN- $\gamma /$ IL-4 in BAL fluid $(p<0.05)$, and expression of T-bet/GATA-3 in the spleen $(p<0.05)$.

Conclusions: HSP70/CD80 DNA vaccine can inhibit airway remodeling through regulating the development of Th1/Th2 subsets in asthmatic mice.
\end{abstract}

Key words: asthma, airway remodeling, DNA vaccine, GATA-3, T-bet.

\section{Introduction}

Airway remodeling is progressive airway damage and structural changes can be caused by long-term recurrent asthma. Airway remodeling can occur at the early stage of the disease and cause an irreversible persistent airflow obstruction and a gradual decline in lung function in asthma

\section{Corresponding author:} Dr. Chen Zhuang Laboratory of Infection and Immunity Affiliated Hospital of Luzhou Medical College Luzhou 646000 Sichuan, China Phone: +868303165629 Fax: +86 8303165629 E-mail: zhuangchen_99@yahoo.com 
patients [1]. It is critical to further understand the mechanism of airway remodeling and search for the prevention and treatment of remodeling in patients with asthma.

Although inhalation of corticosteroids supplemented [2] by sputum induction is an effective therapy for the control of airway inflammation and asthma symptoms, airway remodeling is actually not restrained during the development of asthma [3]. In addition, there are many side effects that may lead to patients discontinuing the therapy [4]. As one of the most effective therapies, DNA vaccine has turned out to be a promising novel type of immunotherapy against allergy [5]. In previous studies, HSP70/CD80 DNA vaccine showed strong inhibition of airway hyperresponsiveness and airway inflammation in an asthmatic mouse model. The related mechanism may be attributed to the increase of interferon- $\gamma$ (IFN- $\gamma$ ), strength of Th1-type response and changes of the immune balance [6].

The aim of the present study was to demonstrate whether HSP70/CD80 DNA vaccine could inhibit airway remodeling in chronic asthmatic mouse and reveal the potential mechanisms.

\section{Material and methods}

\section{Preparation of HSP70/CD80 DNA vaccine}

The HSP70 gene of mycobacterium tuberculosis and human CD80 were linked together and then cloned into the pcDNA3.1 eukaryotic expression vector. Details of the construction and identification were described in our previous studies [7]. In the present study, large scale preparation of the plasmid HSP70/CD80 was conducted with EndoFree Plasmid Giga Kit (QIAGEN GmbH, Germany) according to the manufacturer's instructions. Plasmids were dissolved in normal saline and adjusted to $1 \mathrm{mg} / \mathrm{ml}$ and stored at $-20^{\circ} \mathrm{C}$.

\section{Animals and antigen challenged airway remodeling}

Female BALB/C mice, 6-8 weeks old, were purchased from the Third Military Medical University and housed in a specific pathogen-free facility. The present study was approved by the Institutional Animal Care and Use Committee and adhered to the principles outlined by the Declaration of Helsinki.

Forty BALB/c mice were divided randomly into a control group, chronic asthma group, pcDNA3.1 group and DNA vaccine group. On days $-42,-28$ and -14 , the pcDNA3.1 group was immunized with pcDNA3.1 plasmid $(100 \mu \mathrm{g}+25 \mu \mathrm{g}$ bupivacaine/ mouse) by intramuscular injection, the DNA vaccine group was treated with HSP70/CD80 $(100 \mu \mathrm{g}+25 \mu \mathrm{g}$ bupivacaine/mouse) by intramuscular injection, and the control group and asthmatic group were treated with phosphate-buffered saline (PBS $+25 \mu \mathrm{g}$ bupivacaine/mouse). Bupivacaine (Jiangsu Hengrui Medicine, Jiangsu, China) is a new class of DNA delivery complexes [8]. Mice were intraperitoneally sensitized using OVA (Sigma-Aldrich, St. Louis, USA) at a concentration of $0.01 \mathrm{mg} / \mathrm{mouse}$ in $0.2 \mathrm{ml}$ of alum on days 0 and 14 . Mice were challenged with 1\% OVA (aerosolized for $30 \mathrm{~min}$ ) via the airways between days 21 and 26. Prolonged challenge was induced by subsequent exposure to aerosolized OVA (1\%) three times a week for 30 min from day 28 to day 70 (Figure 1) in a modified version of McMillan et al.' methods [9]. Control mice were injected and challenged with saline. Mice were then sacrificed by cervical dislocation after anesthesia on day 70 .

\section{Measurement of airway responsiveness}

Twenty-four $h$ after the final challenge, wholebody plethysmography (WBP system, BUXCO, Wilmington, North Carolina USA) was used to measure airway responsiveness. Increasing doses of methacholine (MCh, Wako, Osaka, Japan) (1.5, 3, 6, 24, and $48 \mathrm{mg} / \mathrm{ml}$ ) were inhaled at approximately 3-min intervals, and enhanced pause (Penh) results were recorded. This protocol is a modification of the method of Kearley et al. [10].

\section{Bronchoalveolar lavage collection and measurement of cytokines}

Before sacrifice, the mice were anesthetized by $2 \%$ pentobarbital sodium (Sigma-Aldrich, St. Louis, USA) with intraperitoneal injections. After tracheal

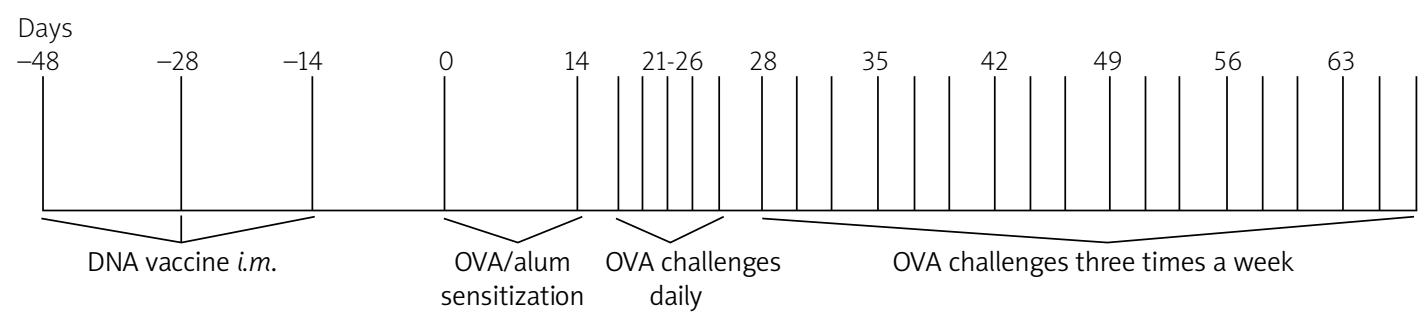

Figure 1. Experimental scheme for OVA-induced airway remodeling. Airway remodeling was induced by sensitization and challenge of ovalbumin in BALB/c mice. The BALB/C mice were immunized with HSP70/CD80 DNA vaccine on days $-42,-28$ and -14 
exposure and cannulation, the airways of the mice were gently instilled with $400 \mu \mathrm{l}$ of cold PBS. This was repeated two additional times. The volume of bronchoalveolar lavage (BAL) fluid was recorded. The BAL fluid was centrifuged $\left(500 \times \mathrm{g}, 5 \mathrm{~min}, 4^{\circ} \mathrm{C}\right)$ and the resulting supernatants were concentrated equally by 10,000 MWCO (cat \#42406, Millipore, MA, USA). Protein concentration was measured by a Lowry based method (DC assay, Bio-Rad, Hercules, CA, USA). All samples were duplicated at $4.8 \mu \mathrm{g}$ protein each in $\mathrm{dH}_{2} \mathrm{O}$, and stored at $-70^{\circ} \mathrm{C}$, as previously described [11]. The levels of IFN- $\gamma$ and IL-4 were measured by ELISA kit (RD systems, Minneapolis, MN, USA) according to the manufacturer's protocol.

\section{Lung tissue histopathology and morphometry}

Lungs were fixed overnight in 10\% normal-buffered formalin. Four $\mu \mathrm{m}$ paraffin-embedded sections were stained with hematoxylin and eosin $(H \& E)$, periodic acid-Schiff (PAS, MAIXIN-Bio, Fuzhou, China), Masson's Trichrome stain (MAIXIN-Bio, Fuzhou, China), and PCNA (pAb, Bioworlde, MN, USA).

\section{Quantification of general morphology}

Image analysis was performed on HE-stained lung sections using ImagePro Plus 6.0 (Media Cybernetics, USA). Digital photographs of four bronchioles at the same level from each group of mice were taken at $40 \times$ magnification and the outer perimeter (Po), internal perimeter $(\mathrm{Pi})$, airway wall area (Awa), airway wall thickness (Awt) and airway basement membrane perimeter ( $\mathrm{Pbm}$ ) were measured. We used $\mathrm{Po} / \mathrm{Pi}, \mathrm{Awa} / \mathrm{Pb}$ and Awt/Pbm to evaluate quantification of airway remodeling.

\section{Assessment of airway mucus production}

Mucus-producing goblet cells were counted using PAS staining. Goblet cells of 5 to 10 consecutive bronchioles from each group of mice were categorized according to a scoring method as follows [11]: less

Table I. Genes and primers of real-time PCR

\begin{tabular}{|lll|}
\hline Gene & Place & Primers (5'-3') \\
\hline IFN- $\gamma$ & Forward & AACTCAAGTGGCATAGATGTGGAAG \\
\hline IFN- $\gamma$ & Reverse & GACGCTTATGTTGTTGCTGATGG \\
\hline IL-4 & Forward & TTTTGAACGAGGTCACAGGAGAGG \\
\hline IL-4 & Reverse & CCTTGGAAGCCCTACAGACGAG \\
\hline T-bet & Forward & GGG GAG GCT ATT TAT TGT \\
\hline T-bet & Reverse & AGA AGG AGG GCG TGT T \\
\hline GATA-3 & Forward & GCT GGA TGG CGG CAA AGC \\
\hline GATA-3 & Reverse & GGT GGG CGG GAA GGT GAA G \\
\hline$\beta$-Actin & Forward & AAT CGT GCG TGA CAT CAA AGA G \\
\hline$\beta$-Actin & Reverse & CCA AGA AGG AAG GCT GGA AAA \\
\hline
\end{tabular}

than $5 \%$ goblet cells are 0 points; $5-25 \%$ goblet cells are 1 point; $25-50 \%$ goblet cells are 2 points; $50-75 \%$ goblet cells are 3 points; more than $75 \%$ goblet cells are 4 points. The mean of each group was expressed as the histological goblet cell score.

\section{Analysis of extracellular matrix deposition}

The tissues were observed for extracellular matrix deposition using Masson Trichrome stain. Four bronchioles at the same level from each group of mice were selected randomly, then digital photographs were taken at 40x magnification and converted into monochrome. Ten measurements of 20$\mu \mathrm{m}$ lines perpendicular to the basement membrane were drawn from the four bronchioles of each mouse. The mean density of Masson Trichrome staining intensity was measured and expressed as pixels $/ \mu \mathrm{m}^{2}$, by the method of Flood-Page [12].

\section{Assessment of ASM cells}

Proliferating cell nuclear antigen (PCNA) was identified as an antigen that is expressed in proliferating cells during $S$ phase of the cell cycle. The sections of each group were also stained immunohistochemically using anti-PCNA antibody. ASM cells in bronchiolar regions were counted at 40x magnification. Positive cells for PCNA stained with the nuclei dark brown. Total ASM cells and ASM cells positive for PCNA were counted and averaged using a modified method [9].

\section{Detection of IFN- $\gamma$, IL-4, T-bet and GATA-3 in spleen by real-time PCR}

Spleens were stored at $-80^{\circ} \mathrm{C}$ until use. Total RNA was isolated from murine spleen tissue using RNAsimple Total RNA kit (TINGEN, Beijing, China) and thereafter reverse transcribed into CDNA using RNA PCR Kit (AMV) Ver. 3.0 (TaKaRa, Dalian, China). Primers of IFN- $\gamma$, IL-4, T-bet, GATA- 3 and $\beta$-action were designed by Sangon Biotech (Shanghai, China). The sequence of primers was as follows (Table I). Quantitative real-time PCR was performed on an iCycler iQ ${ }^{\text {TM }}$ Real-Time PCR Detection System (BioRad, Hercules, CA, USA) according to the manufacturer's instructions for relative quantification. Relative expression of target genes was determined with the Pfaffl method according to the Bio-Rad iQ5 software system.

\section{Statistical analysis}

Data were expressed as mean \pm standard error per group of 5-10 mice from 4 different experiments. Data were analyzed by SPSS 16.0 statistical software with ANOVA or Kruskal-Wallis $H$ test and Mann-Whitney $U$ test. Statistical significance was defined as $p$ values less than 0.05 . 
Table II. Changes of airway responsiveness in each group after stimulation with different concentrations of methacholine $(\%, \bar{x} \pm \mathrm{s})$

\begin{tabular}{|lccccccc|}
\hline Group & No. & $1.5 \mathrm{mg} / \mathrm{ml}$ & $3.0 \mathrm{mg} / \mathrm{ml}$ & $6.0 \mathrm{mg} / \mathrm{ml}$ & $12 \mathrm{mg} / \mathrm{ml}$ & $24 \mathrm{mg} / \mathrm{ml}$ & $48 \mathrm{mg} / \mathrm{ml}$ \\
\hline Control & 10 & $12.45 \pm 33.71$ & $15.44 \pm 31.96$ & $33.27 \pm 3.81^{\mathrm{b}}$ & $97.69 \pm 11.62^{\mathrm{b}}$ & $137.64 \pm 5.95^{\mathrm{b}}$ & $184.76 \pm 97.52^{\mathrm{b}}$ \\
\hline Chronic asthma & 10 & $39.52 \pm 43.36$ & $67.77 \pm 62.38$ & $149.62 \pm 9.58^{\mathrm{a}}$ & $288.46 \pm 11.42^{\mathrm{a}}$ & $338.11 \pm 9.80^{\mathrm{a}}$ & $380.74 \pm 10.59^{\mathrm{a}}$ \\
\hline pcDNA & 10 & $31.08 \pm 50.48$ & $55.50 \pm 60.08$ & $107.43 \pm 7.87^{\mathrm{a}}$ & $252.56 \pm 19.29^{\mathrm{a}}$ & $286.82 \pm 17.92^{\mathrm{a}}$ & $381.73 \pm 21.09^{\mathrm{a}}$ \\
\hline DNA vaccine & 10 & $3.51 \pm 23.39$ & $14.49 \pm 29.52$ & $59.24 \pm 5.78^{\mathrm{b}}$ & $150.89 \pm 9.37^{\mathrm{b}}$ & $217.02 \pm 11.17^{\mathrm{b}}$ & $238.65 \pm 9.29^{\mathrm{b}}$ \\
\hline$F$ & & 1.439 & 2.45 & 3.732 & 3.202 & 3.865 & 4.066 \\
\hline Value of $p$ & & $>0.05$ & $>0.05$ & $<0.05$ & $<0.05$ & $<0.05$ & $<0.05$ \\
\hline
\end{tabular}

aCompared with control mice, $p<0.05$, bcompared with chronic asthmatic mice, $p<0.05$

\section{Results}

\section{Airway responsiveness}

As seen in Figure 2, airway responsiveness in sensitization of mice with allergen (chronic asthma group) was significantly increased at 6, 12, 24 and $48 \mathrm{mg} / \mathrm{ml}$ MCh-inhaled doses compared with control $(p<0.05)$. Mice treated with HSP70/CD80 DNA vaccine had an inhibition effect of airway responsiveness compared with chronic asthmatic mice ( $p<0.05$, more than $6 \mathrm{mg} / \mathrm{ml}$ MCh-inhaled doses). Treatment with pcDNA3.1 plasmid had little effect on airway responsiveness (Table II).

\section{Inhibition of airway wall thickness by DNA vaccine}

The effect of HSP70/CD80 DNA vaccine on airway remodeling in lung tissue histology was determined by staining lung tissue with $\mathrm{HE}(p<0.05$, Figure 3$)$. Prolonged OVA challenge of chronic asthmatic mice results in increased airway wall thickness in comparison to control mice ( $p<0.05$, Figure 4$)$. In contrast, airway wall thickness was reduced in lungs from mice treated with HSP70/CD80 DNA vaccine in comparison to chronic asthmatic mice $(p<0.05$, Figure 4). Treatment with pcDNA3.1 plasmid had little effect on airway wall thickness. There was no significant difference during infiltration of inflammatory cells in bronchioles of mice in each group (Table III).

\section{Reduction of mucus production by DNA vaccine}

As shown in Figure 5, mucus-producing goblet cells were increased in the chronic asthmatic mice model in comparison to control mice $(p<0.05)$. $\mathrm{HSP70/CD80} \mathrm{DNA} \mathrm{vaccine} \mathrm{treatment} \mathrm{reduced} \mathrm{the}$ number of PAS-positive goblet cells in comparison to chronic asthmatic mice ( $p<0.05$, Figure 6$)$. There was no significant difference between pcDNA3.1 plasmid and chronic asthmatic mice.

\section{Inhibition of extracellular matrix deposition by DNA vaccine}

Subepithelial extracellular matrix deposition of chronic asthmatic mice was increased in compari-

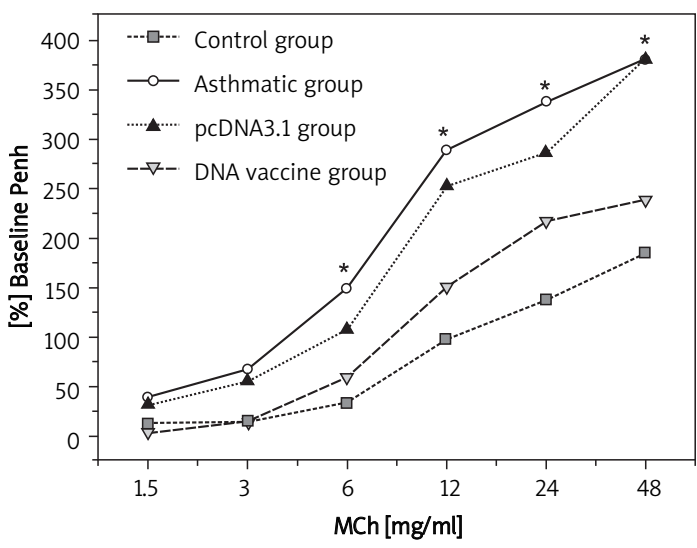

Figure 2. Changes of airway responsiveness in each group after stimulation with different concentrations of methacholine. Airway responsiveness was measured and expressed as mean enhanced pause (Penh) after the final challenge

${ }^{*} p<0.05$ between the indicated groups. Data are shown as mean \pm standard deviations (SD)

son to control mice. Figure 7 and Table IV show that treatment with HSP70/CD80 DNA vaccine reduced peribronchiolar matrix deposition in comparison to chronic asthmatic mice. Treatment with pcDNA3.1 plasmid showed little effect on extracellular matrix deposition.

\section{Inhibition of ASM cell proliferation by DNA vaccine}

Positive PCNA staining ASM cells showed as cells with dark brown elongated or round nuclei. Figure 8 shows that the chronic asthmatic mice model had an increase in the number of total and PCNA-positive ASM cells in the smooth muscle mass in comparison to control mice $(p<0.05)$. Treatment with $\mathrm{HSP70/CD80} \mathrm{DNA} \mathrm{vaccine} \mathrm{significantly} \mathrm{reduced} \mathrm{the}$ number of total and PCNA-positive ASM cells $(p<0.05$, Figure 9) in comparison to chronic asthmatic mice. Treatment with pcDNA3.1 plasmid had little effect on the increase in ASM cell numbers (Table V).

\section{Effect of DNA vaccine on cytokine production}

The BAL fluid from all four groups of mice was recovered and analyzed for the presence of the Th1 

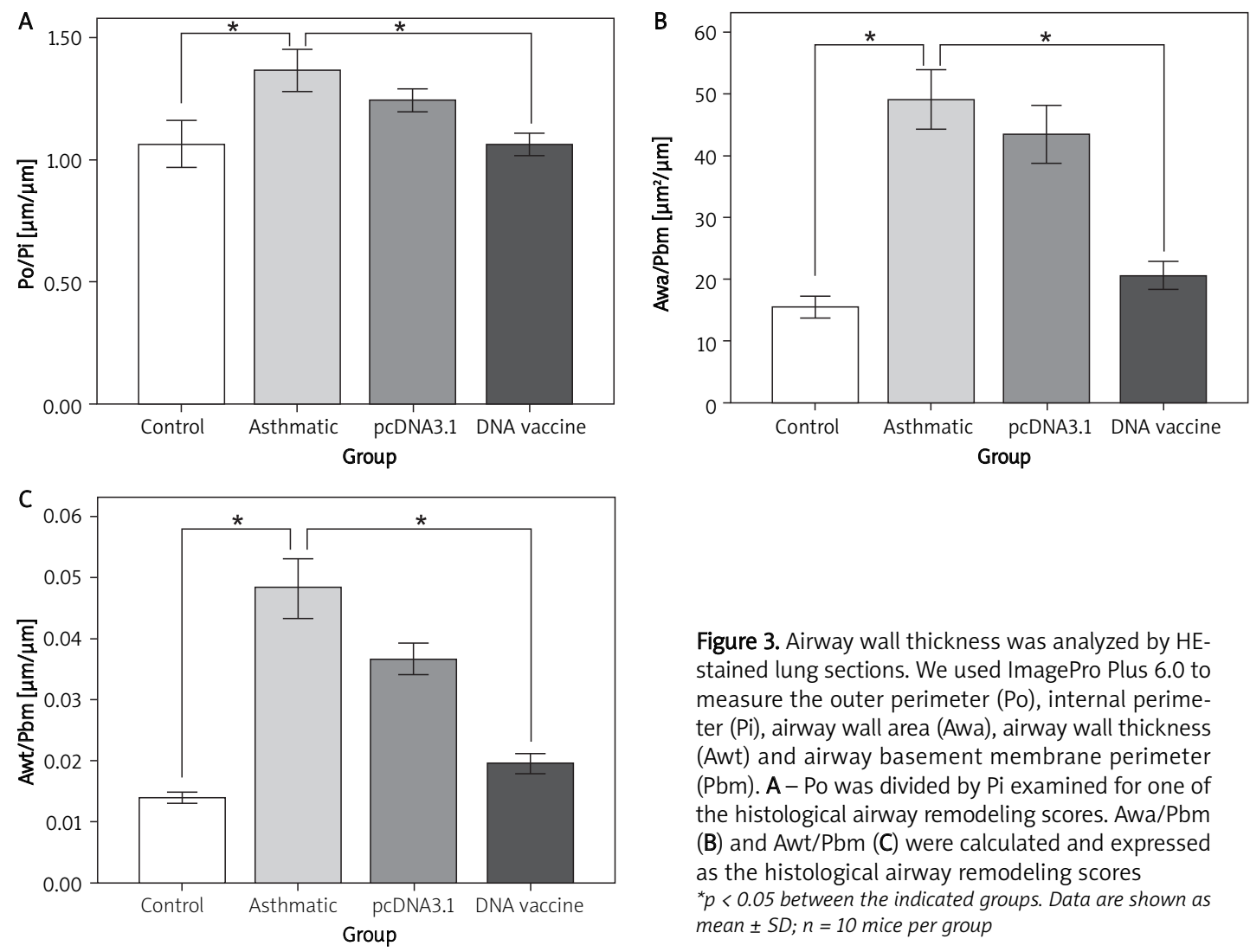

Figure 3. Airway wall thickness was analyzed by HEstained lung sections. We used ImagePro Plus 6.0 to measure the outer perimeter (Po), internal perimeter (Pi), airway wall area (Awa), airway wall thickness (Awt) and airway basement membrane perimeter (Pbm). A - Po was divided by Pi examined for one of the histological airway remodeling scores. Awa/Pbm (B) and Awt/Pbm (C) were calculated and expressed as the histological airway remodeling scores ${ }^{*} p<0.05$ between the indicated groups. Data are shown as mean $\pm S D ; n=10$ mice per group
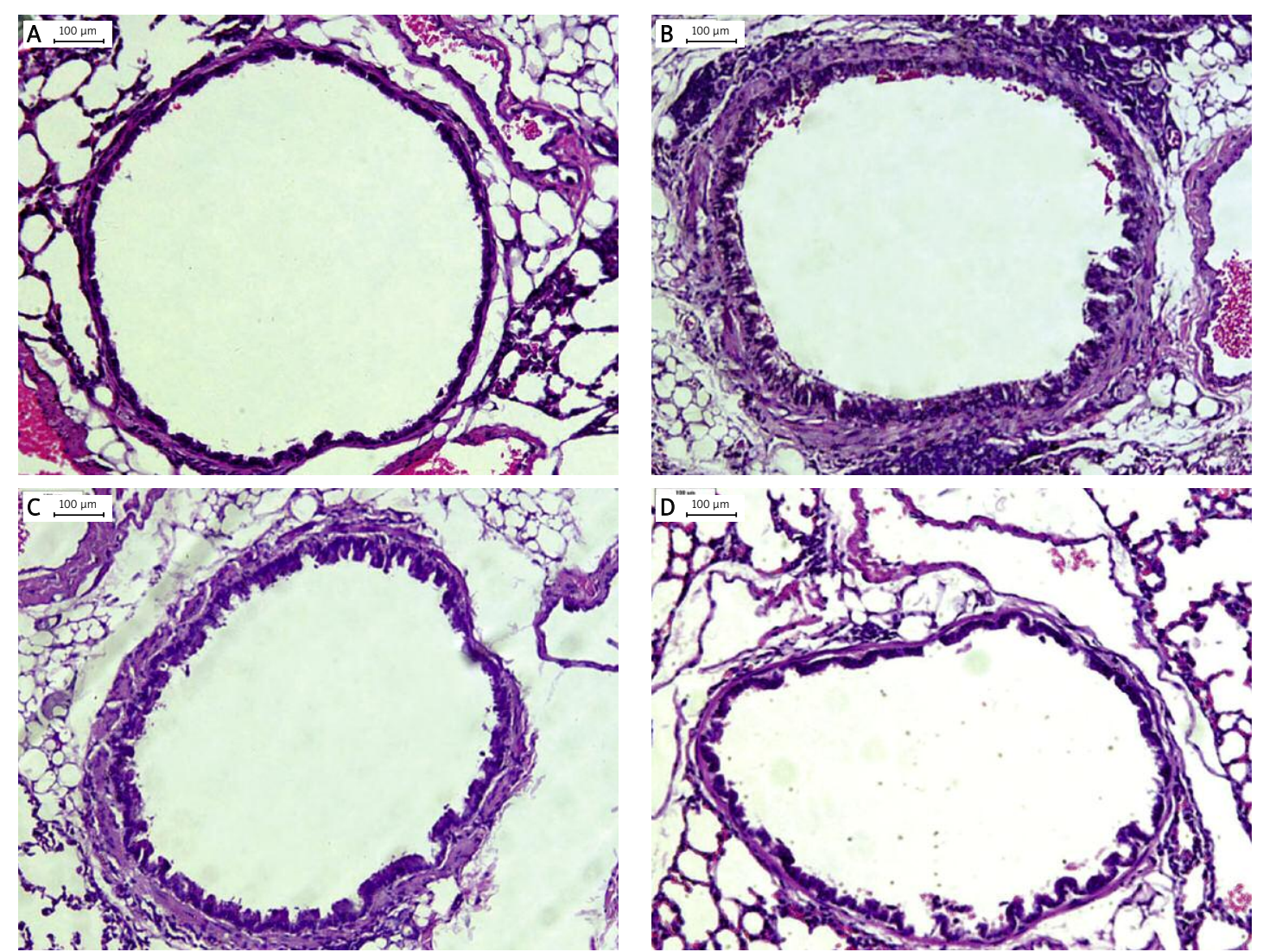

Figure 4. HSP70/CD80 DNA vaccine treatment inhibits airway wall thickness. Representative photomicrographs of $\mathrm{HE}$-stained lung sections from control mouse (A), chronic asthmatic mouse (B), and mouse treated with pcDNA3.1 (C) and HSP70/CD80 DNA vaccine (D). Magnification 100x 
Table III. Morphological parameters of airway remodeling in each group $(\bar{x} \pm \mathrm{s})$

\begin{tabular}{|lcccc|}
\hline Group & No. & Po/Pi $[\mu \mathrm{m} / \mu \mathrm{m}]$ & Awt/Pbm $[\mu \mathrm{m} / \mu \mathrm{m}]$ & $\mathrm{Awa} / \mathrm{Pbm}\left[\mu \mathrm{m}^{2} / \mu \mathrm{m}\right]$ \\
\hline Control & 10 & $1.06 \pm 0.12^{\mathrm{b}}$ & $0.014 \pm 0.0024^{\mathrm{b}}$ & $15.40 \pm 2.27^{\mathrm{b}}$ \\
\hline Chronic asthma & 10 & $1.36 \pm 0.12^{\mathrm{a}}$ & $0.0484 \pm 0.0155^{\mathrm{a}}$ & $49.06 \pm 6.71^{\mathrm{a}}$ \\
\hline pcDNA3.1 & 10 & $1.24 \pm 0.06^{\mathrm{a}}$ & $0.0367 \pm 0.0081^{\mathrm{a}}$ & $43.52 \pm 6.555^{\mathrm{a}}$ \\
\hline DNA vaccine & 10 & $1.06 \pm 0.06^{\mathrm{b}}$ & $0.0196 \pm 0.0052^{\mathrm{b}}$ & $20.45 \pm 3.17^{\mathrm{b}}$ \\
\hline F & & 25.732 & 27.292 & 31.22 \\
\hline Value of $p$ & & $<0.05$ & $<0.05$ & $<.05$ \\
\hline
\end{tabular}

aCompared with control mice, $p<0.05,{ }^{b}$ compared with chronic asthmatic mice, $p<0.05$
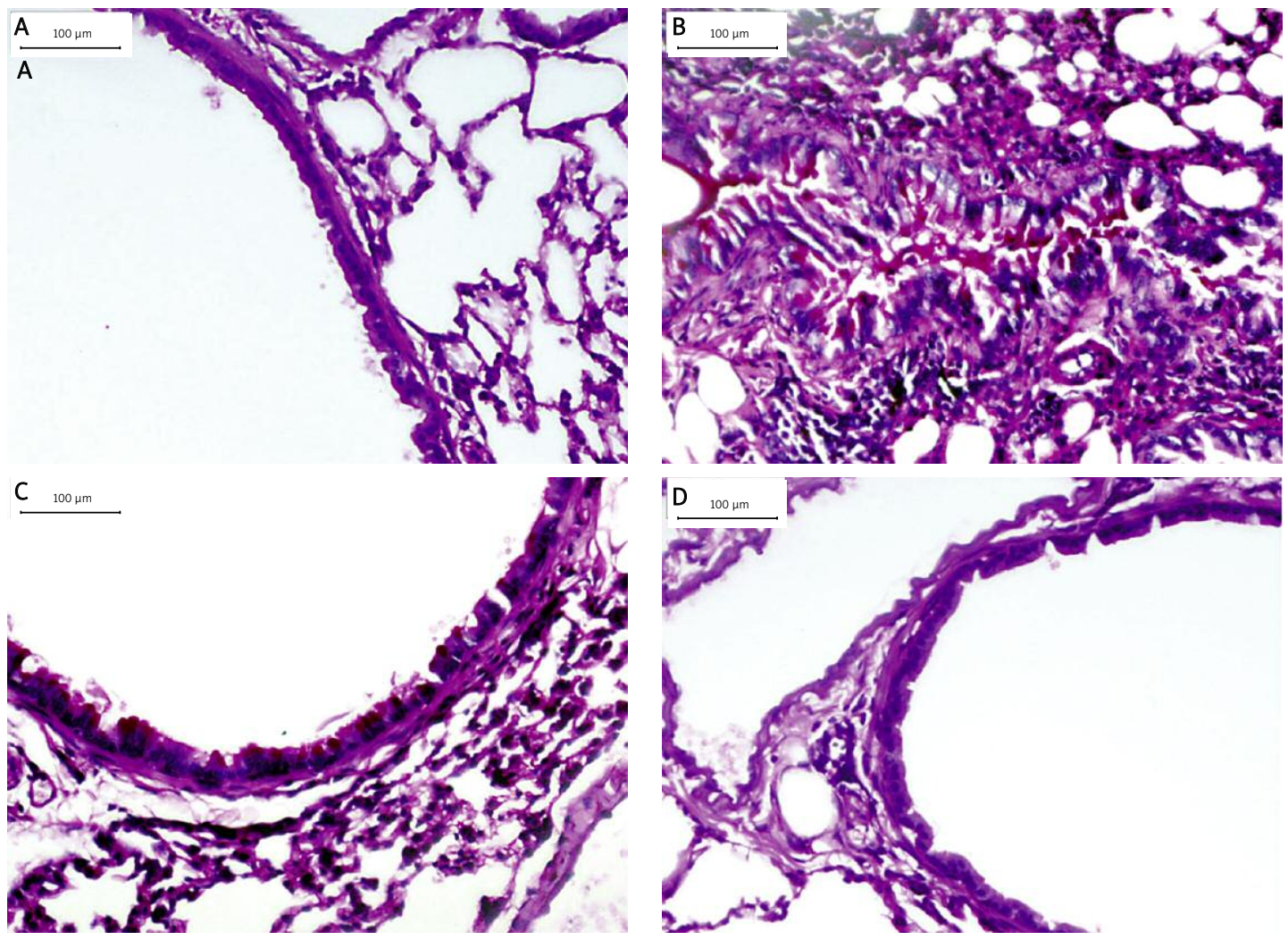

Figure 5. Therapeutic administration of HSP70/CD80 DNA vaccine decreased mucus-producing goblet cells. Representative photomicrographs of PAS-stained lung sections from control mouse (A), chronic asthmatic mouse (B), and mouse treated with pcDNA3.1 (C) and HSP70/CD80 DNA vaccine (D). Magnification 200x

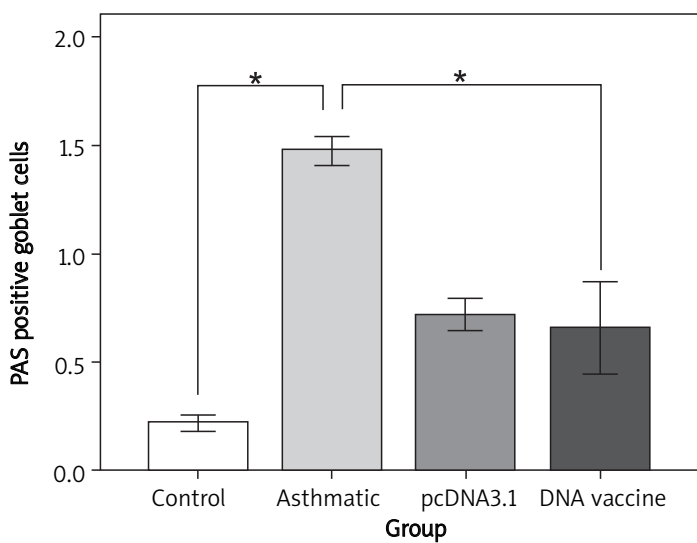

B

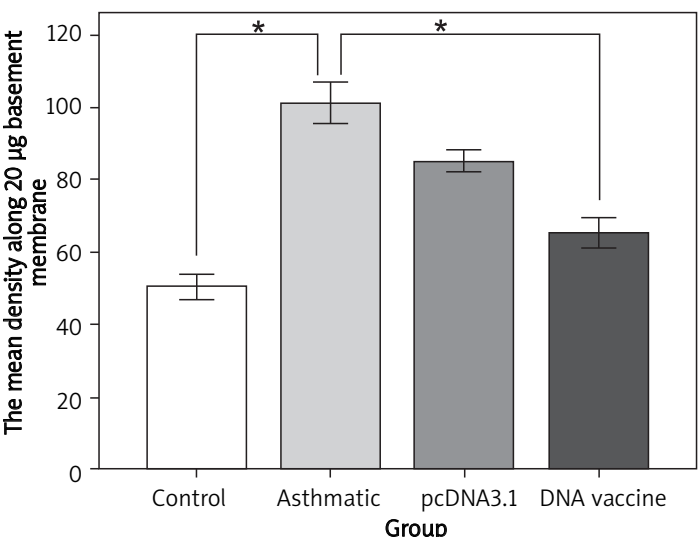

Figure 6. We examined counted mucus-producing goblet cells (A) and the mean density along $20 \mu \mathrm{m}$ basement membrane (B)

${ }^{*} p<0.05$ between the indicated groups. Data are shown as mean $\pm S D ; n=10$ mice per group 

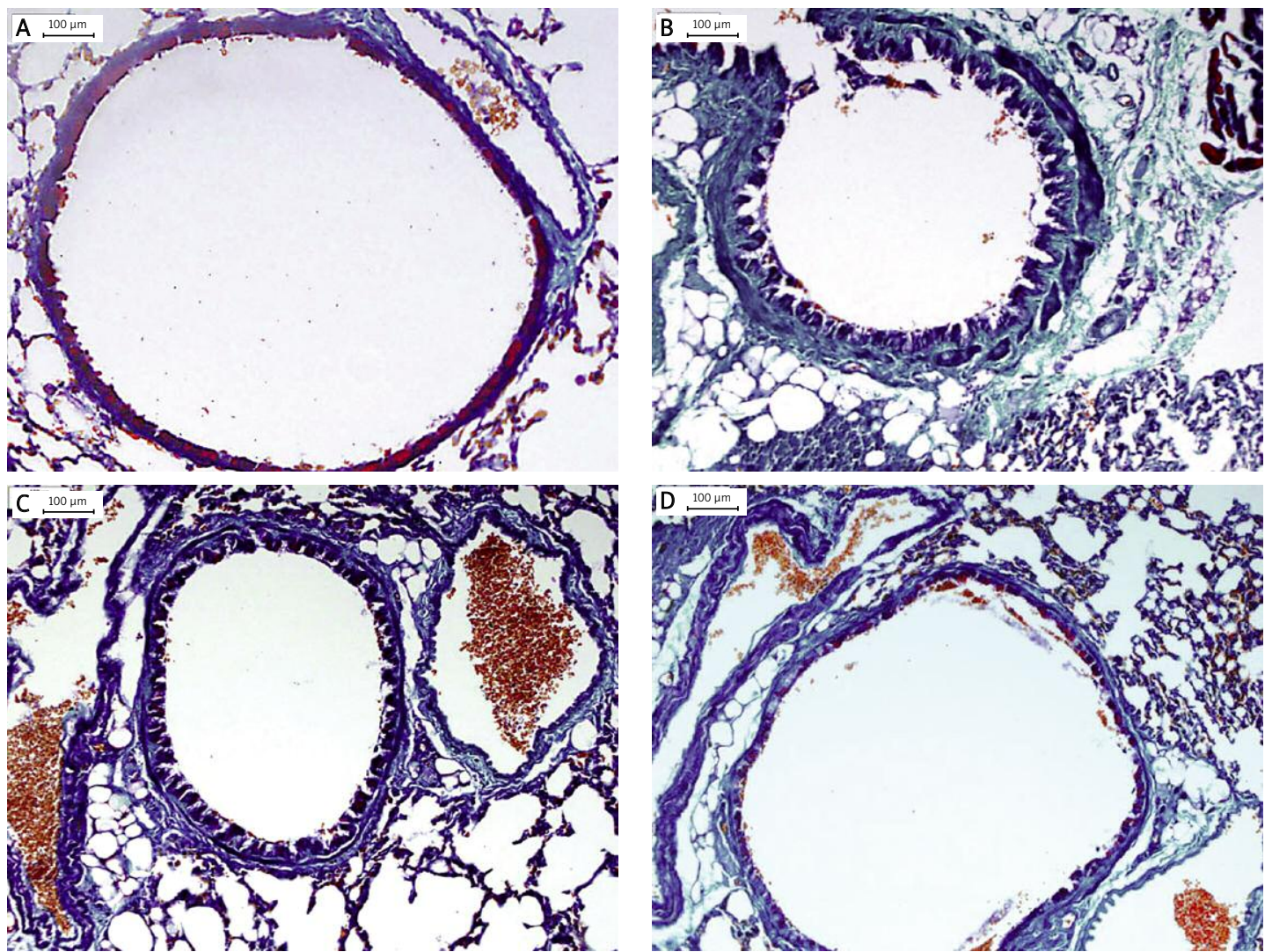

Figure 7. Therapeutic administration of HSP70/CD80 DNA vaccine inhibited extracellular matrix deposition. Representative photomicrographs of Masson Trichrome-stained lung sections from control mouse (A), chronic asthmatic mouse (B), and mouse treated with pcDNA3.1 (C) and HSP70/CD80 DNA vaccine (D). Magnification 200x

Table IV. Changes of PAS positive goblet cell number and extracellular matrix deposition in lung tissue of each group $(\bar{x} \pm s)$

\begin{tabular}{|lccc|}
\hline Group & No. & $\begin{array}{c}\text { PAS positive } \\
\text { cells }\end{array}$ & $\begin{array}{c}\text { Mean density } \\
\text { along } 20 \mu \mathrm{m} \\
\text { basement } \\
\text { membrane }\end{array}$ \\
\hline Control & 10 & $0.20 \pm 0.01^{\mathrm{b}}$ & $50.597 \pm 4.39^{\mathrm{b}}$ \\
\hline Chronic asthma & 10 & $1.50 \pm 0.01^{\mathrm{a}}$ & $101.31 \pm 7.86^{\mathrm{a}}$ \\
\hline pcDNA3.1 & 10 & $0.80 \pm 0.05^{\mathrm{a}}$ & $85.26 \pm 4.25^{\mathrm{a}}$ \\
\hline DNA vaccine & 10 & $0.40 \pm 0.01^{\mathrm{b}}$ & $65.47 \pm 5.82^{\mathrm{b}}$ \\
\hline F & & 18.822 & 148.459 \\
\hline Value of $p$ & & $<0.05$ & $<0.05$ \\
\hline
\end{tabular}

aCompared with control mice, $p<0.05,{ }^{b}$ compared with chronic asthmatic mice, $p<0.05$

cytokine IFN- $\gamma$ and the Th2 cytokine IL-4. As seen in Table II, the level of IFN- $\gamma$ and ratio of IFN- $\gamma / \mathrm{IL}-4$ in the BAL fluid of chronic asthmatic mice were lower than controls $(p<0.05)$. There was a striking increase in the amount of IFN- $\gamma$ and ratio of IFN- $\gamma$ / IL-4 in BAL fluid from HSP70/CD80 DNA vaccinetreated mice in comparison to chronic asthmatic mice $(p<0.05)$. There was no significant difference in IL-4 BAL fluid of mice in each group (Table VI).

\section{Expression of IFN- $\gamma$, IL-4, T-bet} and GATA-3 in spleen tissue

Th1-type transcription factor T-bet and Th2-type transcription factor GATA-3 play the key role in differentiation toward Th1 and Th2 cells. As shown in Table VII, expression of IFN- $\gamma$ was increased in mice treated with HSP70/CD80 DNA vaccine, while expression of IL-4 was decreased in comparison to chronic asthmatic mice. Expression of GATA-3 in the chronic asthmatic mice was significantly higher than in control mice. Mice with HSP70/CD80DNA vaccine showed reduced expression of GATA-3. As shown in Table VII, the ratio of T-bet/GATA-3 mRNA in HSP70/CD80 DNA vaccine-treated mice was significantly higher than in asthmatic mice $(p<0.05)$.

\section{Discussion}

Heat shock protein (HSP)-derived peptides have been shown to promote the production of antiinflammatory cytokines in patients with chronic inflammatory disease, indicating that HSPs have immunoregulatory potential [13]. Heat-shock protein 70 (HSP70) can induce a Th1-type immune response and inhibits or arrests inflammatory damage [14]. Hsp70 was demonstrated to have anti-inflammatory responses in experimental models of auto- 

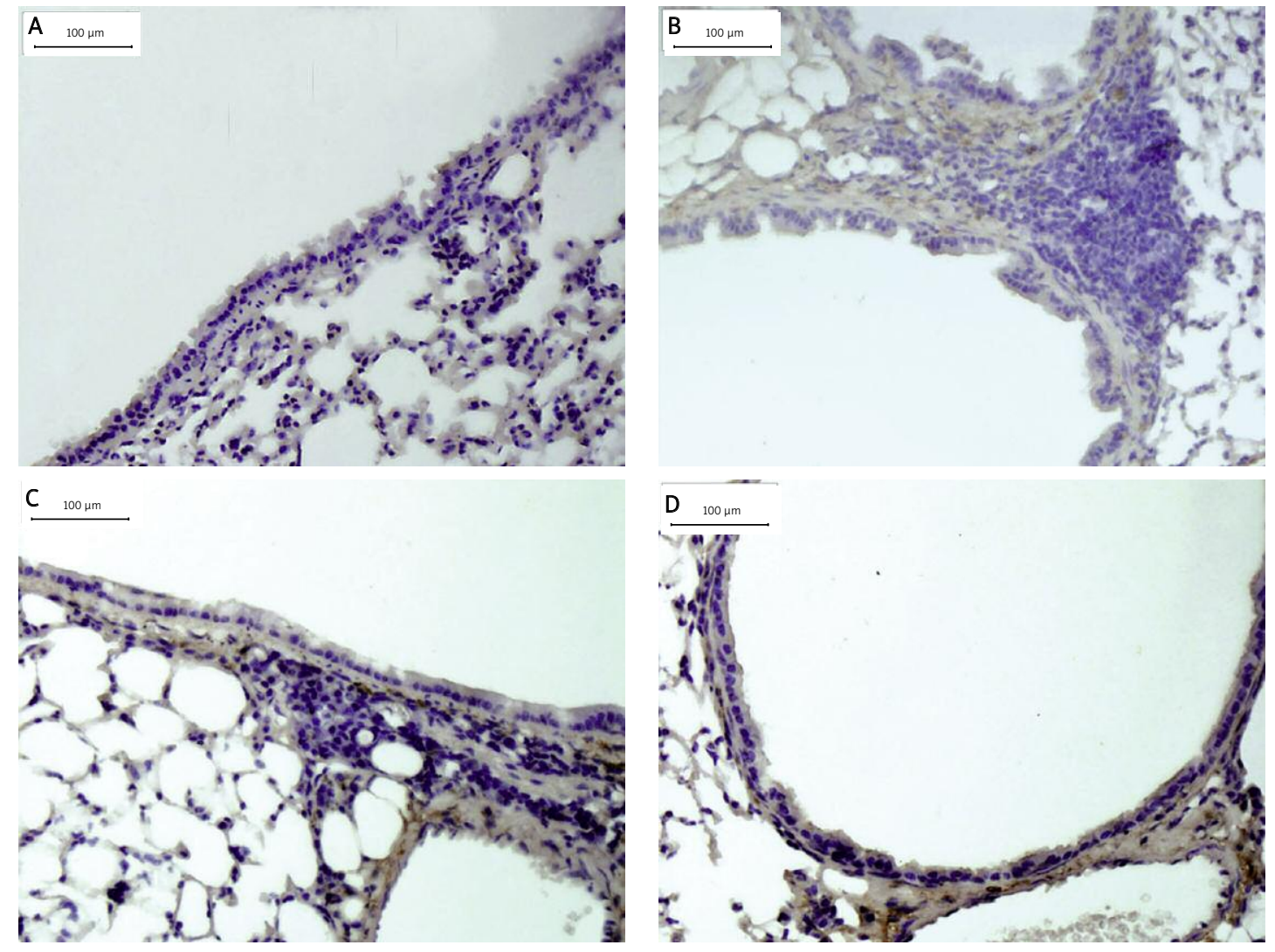

Figure 8. Therapeutic administration of HSP70/CD80 DNA vaccine decreased ASM-like cell proliferation. Representative photomicrographs of PCNA-stained lung sections from control mouse (A), chronic asthmatic mouse (B), and mouse treated with pcDNA3.1 (C) and HSP70/CD80 DNA vaccine (D). Magnification 200x
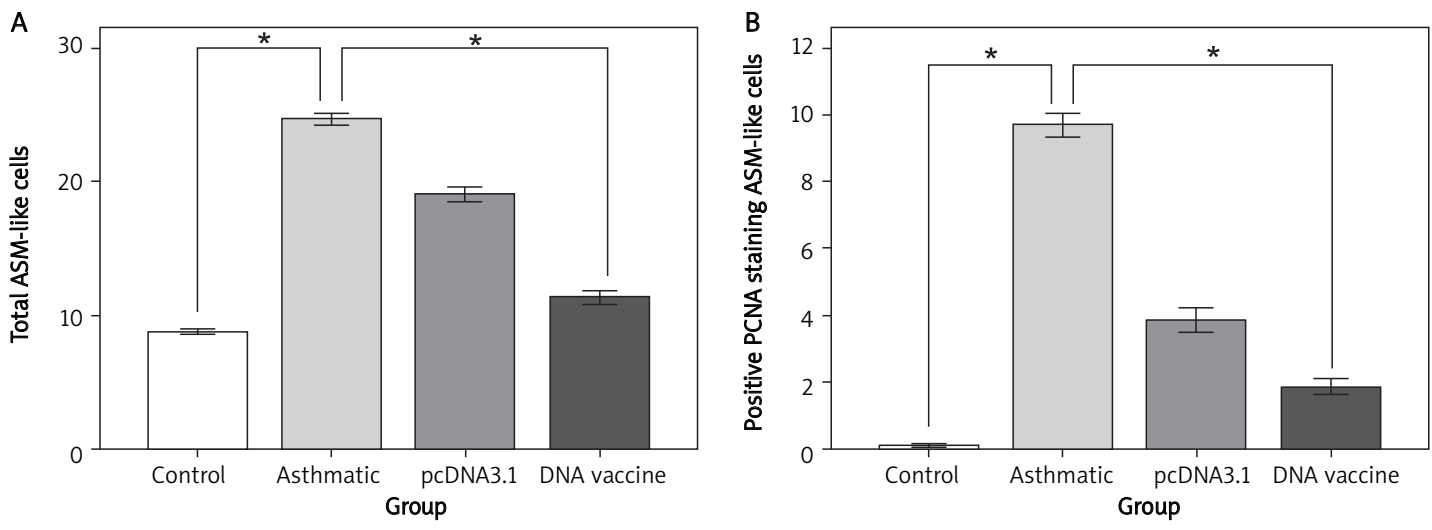

Figure 9. Paraffin-embedded lung tissue sections were stained with anti-PCNA antibody or control antibody. Total ASM cells in bronchiolar regions (A) and those positive for PCNA (B) were counted

${ }^{*} p<0.05$ between the indicated groups. Data are shown as mean $\pm S D ; n=10$ mice per group

immunity [15]. One study revealed that HSP 70 can protect cells under stress and may become a therapeutic target in DM cause's aortic stiffness [16]. Complete T-cell activation requires two distinct signals, one delivered via the T-cell receptor, and the second a "co-stimulatory" signal through B7/CD28 ligation. Some seminal reports suggested that ligation of CD28 to B7-1 (CD80) had effects on the promotion of a Th1 phenotype [17]. We postulated that inoculation of HSP70 and CD80 might affect the development of airway remodeling because expres- sion of HSP70 and CD80 is regulated in the immune imbalance following allergen challenge. In the present study, administration of HSP70/CD80 DNA vaccine before being sensitized and challenged by OVA during prolonged allergen challenge reduced airway remodeling by decreases in airway responsiveness, airway wall thickness, mucus-producing goblet cells, subepithelial extracellular matrix deposition and ASM cells. We observed very little antiremodeling effect in pcDNA3.1 plasmid-treated mice as compared with control mice. This is presumably 
Table V. Changes of ASM cell number in lung tissue in each group $(\bar{x} \pm \mathrm{s})$

\begin{tabular}{|lccc|}
\hline Group & No. & $\begin{array}{c}\text { Total ASM-like } \\
\text { cells }\end{array}$ & $\begin{array}{c}\text { Positive PCNA } \\
\text { staining } \\
\text { ASM-like cells }\end{array}$ \\
\hline Control & 10 & $8.76 \pm 0.45^{\mathrm{b}}$ & $0.08 \pm 0.01^{\mathrm{b}}$ \\
\hline Chronic asthma & 10 & $24.65 \pm 1.01^{\mathrm{a}}$ & $9.68 \pm 0.08^{\mathrm{a}}$ \\
\hline pcDNA3.1 & 10 & $19.04 \pm 1.09^{\mathrm{a}}$ & $3.84 \pm 0.08^{\mathrm{a}}$ \\
\hline DNA vaccine & 10 & $11.32 \pm 1.18^{\mathrm{b}}$ & $1.84 \pm 0.05^{\mathrm{b}}$ \\
\hline$F$ & & 273.508 & 217.673 \\
\hline Value of $p$ & $<0.05$ & $<0.05$ \\
\hline
\end{tabular}

aCompared with control mice, $p<0.05,{ }^{b}$ compared with chronic asthmatic mice, $p<0.05$

because CpG dinucleotide contained by pcDNA3.1 is an immunostimulatory agent [18]. Studies have shown that $\mathrm{CpG}$ oligodeoxynucleotide treatment inhibits airway inflammatory cell infiltration in an asthmatic mouse model $[19,20]$. We have also shown that CpG dinucleotide in pcDNA3.1 has an effect on immune adjuvants and therapeutic administration of HSP70/CD80 DNA vaccine reduces the development of airway remodeling.

Human asthma is heterogeneous in terms of genetics, severity and in all likelihood pathophysiology. The differences between human allergic asthma and mouse models included the disease process, techniques for pulmonary function measurement, and species differences in expression of or responses to key cytokines [21]. No animal model completely recapitulates all features of the human disease. Modeling chronic asthma is controversial, because longterm antigenic challenge often leads to eventual downregulation of airway hyperreactivity or triggers extensive pulmonary inflammation [22, 23]. Our protocol in models of experimentally induced chronic asthma included an important modification of the protocol described by McMillan originally. BALB/c mice sensitized to OVA in the study were challenged for aerosolized OVA (1\%) three times a week for $30 \mathrm{~min}$ over a period of up to 8 week in a whole-body inhalation exposure system. The mice maximized the exhibition of airway wall remodeling changes as seen in human asthma [24]. However, no animal model completely recapitulates all features of the human disease. We recognize the limitations of murine models for the study of chronic asthma which entail that results cannot be directly translated into clinical practice, but we hope the results will offer opportunities for investigation of pathogenetic mechanisms and novel therapeutic agents.

It is now widely accepted that $T$ cells play a critical role in the pathogenesis of asthma which is based on a relative increase in Th2 responses in combination with a decrease in Th1 responses [25]. The mechanisms of Th1/Th2 differentiation induced by T-bet/GATA-3 at the molecular level have been identified. T-box transcription factor T-bet regulates differentiation to the Th1 lineage by inducing lineagerestricted target genes, such as IFN- $\gamma$ and IL-12 genes [26], and GATA-3 regulates differentiation to Th2 by inducing genes for IL-4, IL-5 and IL-13 [27, 28].

Table VI. Level of IFN- $\gamma$, IL-4 and ratio of IFN- $\gamma /$ IL-4 in BAL fluid of each group $(\bar{x} \pm \mathrm{s})$

\begin{tabular}{|lcccc|}
\hline Group & No. & \multicolumn{3}{c|}{ BAL fluid } \\
\cline { 2 - 5 } & & IFN- $\gamma[\mathrm{pg} / \mathrm{ml}]$ & IL-4 $[\mathrm{pg} / \mathrm{ml}]$ & IFN- $\gamma / \mathrm{IL}-4$ \\
\hline Control & 5 & $591.01 \pm 151.57^{\mathrm{b}}$ & $0.5029 \pm 0.0939$ & $1217.1 \pm 435.38^{\mathrm{b}}$ \\
\hline Chronic asthma & 5 & $379.65 \pm 92.43^{\mathrm{a}}$ & $0.5288 \pm 0.0657$ & $638.83 \pm 170.26^{\mathrm{a}}$ \\
\hline pcDNA3.1 & 5 & $314.13 \pm 81.48^{\mathrm{a}}$ & $0.4959 \pm 0.0426$ & $926.51 \pm 261.84^{\mathrm{a}}$ \\
\hline DNA vaccine & 5 & $531.93 \pm 132.31^{\mathrm{b}}$ & $0.4660 \pm 0.0406$ & $1147.4 \pm 300.79^{\mathrm{b}}$ \\
\hline$F$ & & 5.535 & 0.755 & 3.567 \\
\hline Value of $p$ & & $<0.05$ & $>0.05$ & $<0.05$ \\
\hline
\end{tabular}

aCompared with control mice, $p<0.05,{ }^{b}$ compared with chronic asthmatic mice, $p<0.05$

Table VII. Gene expression ratio of IFN- $\gamma / \mathrm{IL}-4$ and T-bet/GATA-3 in each group $(\bar{x} \pm s)$

\begin{tabular}{|lccc|}
\hline Group & No. & IFN- $\gamma /$ IL-4 & T-bet/GATA-3 \\
\hline Control & 5 & $1.090 \pm 0.921$ & $1.000 \pm 0.081$ \\
\hline Chronic asthma & 5 & $0.674 \pm 0.843^{c}$ & $0.931 \pm 0.318^{c}$ \\
\hline pcDNA3.1 & 5 & $0.709 \pm 0.967$ & $1.277 \pm 0.194^{\mathrm{a}}$ \\
\hline DNA vaccine & 5 & $2.365 \pm 0.418^{\mathrm{b}}$ & $1.609 \pm 0.196^{\mathrm{b}}$ \\
\hline$F$ & & 3.349 & 10.343 \\
\hline Value of $p$ & & $<0.050$ & $<0.050$ \\
\hline
\end{tabular}

matic mice, $p<0.05$, c compared with control mice, $p>0.050$
T-bet expression is strongly correlated with IFN- $\gamma$ expression and is specifically up-regulated in primary Th cells that differentiate along the Th1 pathway [29]. GATA-3 has been reported to induce chromatin structure changes of the IL-4 locus and increase the production of Th2-type cytokines by regulating STAT6 [30]. Other research suggests that SAP induces NKT cell development and cytokine IL-4 and IFN- $\gamma$ production by promoting expression of GATA-3 and T-bet [31]. In this respect, our data demonstrated that expression of T-bet/GATA-3 is significantly increased after administration of HSP70/CD80 DNA vaccine. 
The expression occurred concomitantly with increased IFN- $\gamma$, decreased mucus production, extracellular matrix deposition and ASM cell proliferation. In contrast, we found no change in levels of Th2 cytokine IL-4 and the expression of IFN- $\gamma /$ IL-4 in spleen. It has also been reported that IFN- $\gamma$ inhibits airway remodeling induced by Th2 and non-Th2 responses [32]. Consistent with this, our present study showed unchanged levels of IL-4 and a marked increase in the IFN- $\gamma$ level in BALF. Alternatively, it is possible that the results reflect the small number of mice studied or HSP70/CD80 DNA vaccine has a weak effect in regulation of Th2 responses in the research.

In conclusion, we have shown that HSP70/CD80 DNA vaccine can reduce airway remodeling by regulating the transcription factors T-bet and GATA-3 and influencing the immunologic response toward a Th1-type pattern. We believe that the results in this study may provide the basis for developing a more effective therapeutic DNA vaccine to prevent and treat airway remodeling in asthma.

\section{Acknowledgments}

Li Yan and Shi Xiao-Ling contributed equally to this work.

This study was supported by a grant from the Science and Technology Department of Sichuan Province (grant no. 2009JY0076). HSP70/CD80 DNA vaccine was constructed in Luzhou Medical College.

\section{References}

1. Chetta A, Foresi A, Del-Donno $M$, et al. Airways remodeling is a distinctive feature of asthma and is related to severity of disease. Chest 1997; 111: 852-7.

2. Majewski S, Cichocki P, Stepnicka-Bindemann M, Górski P. Asthma control, quality of life and successful sputum induction. Arch Med Sci 2011; 7: 840-3.

3. Haahtela T. Lung function decline in asthma and early intervention with inhaled corticosteroids. Chest 2006; 129: 1405-6.

4. Irwin RS, Richardson ND. Side effects with inhaled corticosteroids the physician's perception. Chest 2006; 130: 41-53.

5. Broide DH. DNA vaccines: an evolving approach to the treatment of allergic disorders. Allergy Asthma Proc 2005; 26: 195-8.

6. Cheng ZY, Shi XL, Li Y, et al. The effects of HSP70/CD80 DNA vaccine on airway inflammation and hyperresponsiveness of asthmatic mice. Chin J Microbiol Immunol 2009; 29: 981-6.

7. Li H, Shi XL, Zhong S, Deng CL, Zhang JJ. Construction and identification of the hsp70/CD80 eukaryotic expression plasmid. Chin J Tuber Respir Dis 2002; 25: 244-5.

8. Liu GX, Xu QA, Jin J, et al. Mucosal and systemic immunization with targeted fusion anti-caries DNA plasmid in young rats. Vaccine 2009; 27: 2940-7.

9. McMillan SJ, Xanthou G, Lloyd CM. Manipulation of allergen-induced airway remodeling by treatment with antiTGF-beta antibody: effect on the Smad signaling pathway. J Immunol 2005; 174: 5774-80.

10. Kearley J, Robinson DS, Lloyd CM. CD4+CD25+ regulatory $T$ cells reverse established allergic airway inflammation and prevent airway remodeling. J Allergy Clin Immunol 2008; 122: 617-24.

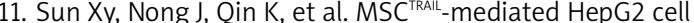
death in direct and indirect co-cultures. Anticancer Res 2011; 31: 3705-12.

12. Flood-Page P, Menzies-Gow A, Phipps S, et al. Anti-IL-5 treatment reduces deposition of ECM proteins in the bronchial subepithelial basement membrane of mild atopic asthmatics. J Clin Invest 2003; 112: 1029-36.

13. Vignola AM, Mirabella F, Costanzo G, et al. Airway remodeling in asthma. Chest 2003; 123: 417-22.

14. Eden WV, van der Zee R, Prakken B. Heat-shock proteins induce T-cell regulation of chronic inflammation. Nat Rev Immunol 2005; 5: 318-30.

15. Borges TJ, Wieten L, van Herwijnen MJ, et al. The antiinflammatory mechanisms of Hsp70[J]. Front Immunol 2012; 3: 95.

16. Ugurlucan M, Erer D, Kalko Y, et al. Aortic stiffness in diabetes mellitus: association with glutamine and heat shock protein 70 expression: a pilot study based on an experimental rodent model. Expert Opin Ther Targets 2009; 13: 267-74.

17. Ndejembi MP, Teijaro JR, Patke DS, et al. Control of memory CD4 T cell recall by the CD28/B7 costimulatory pathway. J Immunol 2006; 177: 7698-706.

18. Weiner GJ. The immunobiology and clinical potential of immunostimulatory CpG oligodeoxynucleotides. J Leukoc Biol 2000; 68: 455-63.

19. Wu ZQ, Xu YP, Xiang H, Shen HH. Effects of CpG oligodeoxynucleotide on transcription factors GATA-3 and Tbet mRNA expression in asthmatic mice. Acta Pharmacol Sin 2005; 26: 1117-22

20. Ashino S, Wakita D, Zhang Y, Chamoto K, Kitamura $H$, Nishimura T. CpG-ODN inhibits airway inflammation at effector phase through down-regulation of antigen-specific Th2-cell migration into lung. Int Immunol 2008; 20: 259-66.

21. Boyce JA, Austen FK. No audible wheezing: nuggets and conundrums from mouse asthma models. J Exp Med 2005; 201: 1869-73.

22. Henderson WR, Tang LO, Chu SJ, et al. A role for cysteinyl leukotrienes in airway remodeling in a mouse asthma model. Am J Respir Crit Care Med 2002; 165: 108-16.

23. Bates JH, Rincon M, Irvin CG. Animal models of asthma. Am J Physiol Lung Cell Mol Physiol 2009; 297: 401-10.

24. Temelkovski JS, Hogan P, Shepherd DP, Foster PS, Kumar RK. An improved murine model of asthma: selective airway inflammation, epithelial lesions and increased methacholine responsiveness following chronic exposure to aerosolised allergen. Thorax 1998; 53: 849-56.

25. Larché $M$. Regulatory T cells in allergy and asthma. Chest 2007; 132: 1007-14.

26. Yeh WI, Harrington LE. Regulation of effector CD4+ T cell functions by Tbet. J Immunol 2009; 182: 48.

27. Cook KD, Miller J. TCR-dependent translational control of GATA-3 enhances Th2 differentiation. J Immunol 2010; 185: 3209-16.

28. Kemp KL, Levin SD, Bryce PJ, Stein PL. Lck mediates Th2 differentiation through effects on T-bet and GATA-3. I Immunol 2010; 184: 4178-84.

29. Szabo SJ, Kim ST, Costa GL, Zhang X, Fathman CG, Glimcher LH. A novel transcription factor, T-bet, directs Th1 lineage commitment. Cell 2000; 100: 655-69.

30. Ouyang W, Lohning M, Gao Z, et al. Stat6-independent GATA-3 autoactivation directs IL-4-independent Th2 development and commitment. J Immunity 2000; 12: 27-37.

31. Cen O, Ueda A, Guzman L, et al. The adaptor molecule signaling lymphocytic activation molecule-associated protein (SAP) regulates IFN-gamma and IL-4 production in Valpha14 Transgenic NKT cells via effects on GATA-3 and T-bet expression. J Immunol 2009; 182: 1370-8.

32. Cohn L, Homer RJ, Niu N, Bottomly K. T helper 1 cells and interferon gamma regulate allergic airway inflammation and mucus production. J Exp Med 1999; 190: 1309-18. 